\title{
Experiências em ensino remoto de Publicidade e Propaganda na pandemia da Covid-19
}

Janderle Rabaiolli

Professor do Departamento de Ciências da Comunicação da Universidade de Santa Maria (UFSM) e doutor em comunicação pela mesma instituição.

E-mail: janderle.rabaiolli@ufsm.br

Fábio Hansen

Docente e Pesquisador no curso de Publicidade e Propaganda e no Programa de Pós-Graduação em Comunicação da Universidade Federal do Paraná (UFPR). Integrante do Grupo de Pesquisa Inovação no Ensino de Publicidade (IEP).

E-mail: fabiohansen@ufpr.br

Resumo: Este artigo relata a experiência da pesquisa "Ensino remoto de Publicidade e Propaganda em tempos de pandemia", realizada com o objetivo de mapear práticas docentes em cursos do campo publicitário na pandemia da covid-19. A coleta de dados ocorreu em maio de 2020 por meio de questionário on-line de autopreenchimento junto a 283 docentes de cursos de Publicidade e Propaganda. O estudo apresenta, entre os principais resultados, o desgaste e o engajamento docente, o despreparo das Instituições de Ensino (IES) e prejuízos à aprendizagem e à qualidade do ensino. Discute-se ainda outros aspectos relevantes do ensino remoto na pandemia, a saber: relação com as IES; condições do trabalho docente; desafios da atuação docente; recursos didáticos empregados; metodologias de ensino; experiências com aulas remotas.

Palavras-chave: publicidade e propaganda; ensino remoto; trabalho docente; práticas de ensino; pandemia da Covid-19.
Abstract: Our article reports the experience of the research "Remote teaching of advertising in times of pandemic", aimed at mapping teaching practices in courses of the advertising field in the Covid-19 pandemic. The data was collected on May 2020 via an on-line self-completion questionnaire with 283 professors from Advertising undergraduate courses. The results of our study show the engagement and distress of teachers, the unpreparedness of educational institutions (IES), and losses to teaching quality. Our study also addresses other relevant aspects of a remote teaching in the pandemic, namely: relationship with IES; teaching work conditions; challenges of teacher's performance didactic resources, teaching methodologies and experiences with remote classes.

Keywords: advertising; remote teaching; teaching work; teaching practices; Covid-19 pandemic. 


\section{INTRODUÇÃO E APRESENTAÇÃO DA PESQUISA}

A pandemia de Covid-19 marca 2020. O fechamento de locais públicos e instituições de ensino, de diferentes níveis, visa conter a disseminação da doença. 190 países com escolas fechadas e 1,57 bilhão de crianças e jovens afetadas, aproximadamente $90 \%$ da população estudantil mundial.

No Brasil, a contaminação levou à suspensão do ensino presencial para colaborar no isolamento social. A interrupção trouxe apreensão. Por parte das instituições, o dilema inicial era suspender ou manter, mesmo que parcialmente, as atividades, frente à imprecisão do período de fechamento. A medida inicial de interromper passou a uma preocupação pela extensão da pandemia e necessidade de evitar aglomerações. A continuidade envolveu ferramentas de tecnologia educacional, discentes e docentes em suas casas - distantes do espaço físico das instituições de ensino.

O ensino presencial, caracterizado pela exposição de conteúdo na presença física e temporal, estava inviabilizado. Adequando-se à nova realidade, não havia condições técnicas, econômicas e humanas para migrar rápida e satisfatoriamente aos ambientes digitais. $\mathrm{O}$ ensino remoto surgiu como alternativa, entre críticas, aceitações, boicotes e sentimentos diversos.

No ensino superior brasileiro, desigualdades são evidentes. Em maio de 2020, segundo o ministério da educação (MEC), seis das 69 universidades federais e $78 \%$ das instituições particulares adotaram o ensino remoto em função da pandemia (dados da Associação Brasileira de Mantenedoras de Ensino Superior - Abmes).

Neste contexto, na condição de docentes de cursos de Publicidade e Propaganda e pesquisadores no Grupo de Pesquisa Inovação no Ensino de Publicidade, problematizamos as condições que envolvem o ensino remoto emergencial. A pesquisa ${ }^{1}$ teve o objetivo geral de mapear práticas no ensino remoto em Publicidade e Propaganda na pandemia da Covid-19 e como objetivos específicos: (1) avaliar percepção e sentimento docente sobre a repentina transformação do processo ensino-aprendizagem; (2) compreender condições, ambiente e relações de trabalho docente da área na pandemia.

Adotamos como instrumento questionários on-line de auto preenchimento na plataforma de Formulários Google. Questionário é uma técnica de investigação com o "propósito de obter informações sobre conhecimentos, crenças, sentimentos, valores, interesses, expectativas, aspirações, temores, comportamento presente ou passado etc." ${ }^{2}$. A participação foi restringida a docentes atuantes no ensino remoto em Publicidade e Propaganda. As questões preponderantes foram fechadas, com escala de cinco alternativas de concordância. Outras

1. Relatório completo da pesquisa está disponível em: https://www.grupoiep. com/cientificos

2. GIL, Antonio Carlos. Métodos e técnicas de pesquisa social. São Paulo: Atlas, 2008. p. 121. abertas buscavam sentimentos e manifestações espontâneas complementares.

Participaram 283 respondentes, de instituições de ensino públicas e privadas, de 5 a 22 de maio de 2020, sendo: 52,4\% do gênero feminino e 47,6\% masculino; $83,5 \%$ residem com familiares e $13,4 \%$, sozinhos; $53,7 \%$ dos respondentes afirmam ter filhos. Geograficamente, a pesquisa alcançou todas as regiões 
brasileiras. 47,2\% afirmam ser de IES privadas, com fins lucrativos; 38,2\% de IES privadas, sem fins lucrativos; e 14,6\% de IES públicas.

O objetivo do presente artigo é relatar a experiência da pesquisa realizada com docentes de Publicidade e Propaganda na pandemia da Covid-19 para compreender as práticas de ensino remoto.

\section{PERCEPÇÕES INICIAIS SOBRE AS CONDIÇÕES DAS AULAS REMOTAS}

Com o intuito de abordar as experiências na atividade educacional remota emergencial, começamos pela implantação do ensino remoto em Publicidade e Propaganda. Identificamos que as atividades não-presenciais iniciaram com aviso e planejamento prévio das IES para 47,2\% dos respondentes ("concordo fortemente" e "concordo moderadamente" somados). Contudo, 29,9\% discordaram da afirmação ("discordo fortemente" e "discordo moderadamente") e outros $22,8 \%$ se mostraram indiferentes. Ao examinar detidamente citações extraídas das questões abertas, destacamos a incipiência do planejamento realizado:

Não tivemos tempo de estudar estratégias. Tivemos que adequar as aulas e o plano de ensino que tínhamos feito para aulas presenciais para o ambiente virtual em dois dias (Respondente 42 - privada);

Não houve tempo para planejamento - mas pensar em um espaço adequado para os professores (com equipamentos adequados) iria facilitar o ensino/aprendizagem neste momento (Respondente 168 - privada).

Diante das respostas, algumas hipóteses: (1) o ensino de Publicidade e Propaganda precisou se reinventar em prazo exíguo; (2) fomos pegos de surpresa, sem tempo de planejar o processo de ensino-aprendizagem; (3) IES privadas não suspenderam o calendário para sobreviver financeiramente e manter empregos.

Logo, as preocupações das IES foram colocadas em tela. Indagados se "A instituição de ensino tem demonstrado e externado preocupação com a situação dos docentes", mais de $55 \%$ dos respondentes concordaram (fortemente ou moderadamente) - Gráfico 1. Contudo, praticamente $45 \%$ estavam indiferentes ou discordaram, sinalizando outras preocupações essenciais das IES. O enunciado a seguir endossa a impressão:

Penso que nesse momento de pandemia, pensou-se na saúde financeira da instituição de ensino, pensou-se em agradar estudantes, mas não se falou sobre o docente. Acredito que seria preciso uma adequação de horários, uma vez que nas aulas presenciais tínhamos atividades em sala programadas. Sei que é preciso pensar no financeiro, manter os empregos, mas o longo tempo, o excesso de trabalho, a reclamação e exigências constantes dos alunos deixam o professor oprimido, esgotado emocionalmente, sem condições de realizar um bom trabalho (Respondente 42 - privada). 


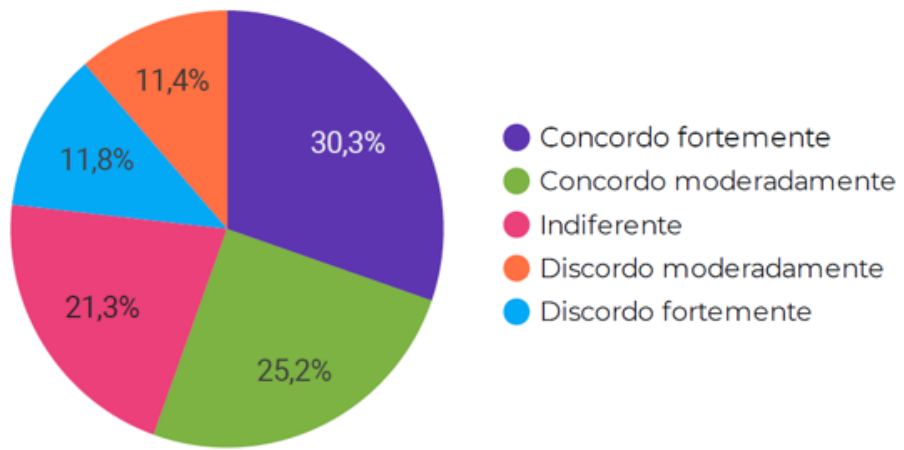

Gráfico 1: A IES tem demonstrado e externado preocupação com a situação dos docentes

Também questionamos a preocupação com os discentes. 75,6\% participantes concordaram ("fortemente" ou "moderadamente" somados) com a afirmação "A instituição de ensino tem demonstrado e externado preocupação com a situação dos discentes”. Todavia, pontuamos que manutenção do vínculo não significa aprendizado: "No momento, nossa principal preocupação - motivados pelas instituições - é muito maior sobre a frequência do aluno em detrimento da a aprendizagem do aluno" (Respondente 182 - privada).

A maior preocupação das IES com os discentes reflete na pergunta que identifica a "Principal preocupação da instituição de ensino nesse momento de pandemia”. Para 45,3\% o foco é a saúde financeira da instituição e para 23,2\% a manutenção do calendário acadêmico. Por extensão, a prioridade das instituições está na própria sobrevivência financeira - o que não deixa de ser legítimo:

Ao manter as aulas, ainda que não presenciais, mantém os alunos pagantes (Respondente 18 - privada);

As universidades deveriam cumprir melhor seu papel na formação cidadã, o foco está apenas no lucro (Respondente 152 - privada).

Em relação a encaminhamentos "No processo de tomada de decisão sobre a manutenção das atividades acadêmicas com aulas não-presenciais (ensino remoto)", 75,6\% apontaram a decisão unilateral da IES. Para 12,6\%, docentes foram consultados. Assim, nota-se parco diálogo para tomada de decisões, incoerente com instâncias educativas. Respostas às questões abertas reforçam tal percepção: "Nem os professores e nem os alunos escolheram estar nessa situação, e a insatisfação e a falta de adaptação de alguns não é necessariamente com a mudança na maneira de ensinar, mas pela falta de escolha" (Respondente 65 - privada). Mesmo com sugestões, docentes sublinharam a posição subalterna na IES: "Sugiro a suspensão do calendário acadêmico, no entanto, não temos voz para isso" (Respondente 109 - privada).

Também perguntamos se "A instituição de ensino ofereceu recursos e suporte para o ensino remoto" e "Disponibilizou plataformas e ferramentas 
digitais para organização de salas de aulas remotas". No primeiro caso, $76 \%$ concordaram (52\% concordam fortemente). Na segunda questão, 89,7\% concordaram $(72,8 \%$ concordam fortemente).

Diante dos resultados expostos, formulamos uma hipótese: o treinamento ofertado, suporte e recursos disponibilizados são insuficientes na pandemia. A pressuposição envolve contribuições como:

Mais treinamentos e oficinas com tempo para cada prática e não tudo jogado rapidamente para 'cumprir tabela' e dizer que disponibilizou oficina (Respondente 58 - privada).

Incrementar as capacitações dos docentes, diversificando a aprendizagem das ferramentas de ensino e avaliação no modo remoto/on-line (Respondente 108 - privada).

Outras reivindicações foram identificadas nos questionamentos abertos que buscavam "Sugestões para as instituições de ensino, colegas e/ou estudantes", prevalecendo recomendações às IES. Identificadas aderências temáticas, agrupamos nos seguintes eixos: diálogo, transparência, cobrança, saúde, emprego e renda.

O diálogo, elemento transversal e inerente a questões de autoria ${ }^{3}$, interação com o outro ${ }^{4}$, participação, vínculo e aprendizagem, relaciona-se com a tomada de decisão sobre a adoção das atividades remotas emergenciais, estratégias adotadas e práticas docentes, como evidenciado nas manifestações:

Para as instituições: construir diálogo com os/as professores/as, pensando conjuntamente sobre soluções e estratégias para o ensino remoto (Respondente 181 - privada).

União e debate pedagógico sobre melhores práticas (Respondente 191 - privada)

É fundamental que se crie um espaço específico de diálogo e trocas, permitindo a participação efetiva de todas as instâncias que compõem o universo acadêmico (Respondente 205 - privada).

Transparência, relacionada às incertezas, para instituições, docentes e discentes. As respostas condizem com perspectivas de fluxo comunicacional, planejamento, organização e segurança aos envolvidos na atividade remota emergencial, evidentes em enunciados como:

As universidades devem apresentar comunicações mais claras aos estudantes e serem transparentes. Abrirem canais para escutar alunos e professores (Respondente 188 - privada);

Transparência nos comunicados: informações imprecisas geram insegurança (Respondente 56 - privada).

Cobrança perpassa, especialmente, a relação entre IES e docentes. Questionados se "A cobrança da Instituição de Ensino por rendimento permanece inalterada, mesmo com a pandemia”, 37,4\% concordaram fortemente e $25,2 \%$ moderadamente e 17,3\% mostraram-se indiferentes. Nas possibilidades de manifestação aberta, reivindicações por "Maior flexibilização nas cobranças de desempenho docente" (Respondente 277 - privada) e elementos para questionar a carga laboral e a saúde docente apareceram intensamente: "Teoricamente
3. AMARAL, Mirian Maia; VELOSO, Maristela Midlej Silva de Araujo; ROSSINI, Tatiana Stofella Sodré. A autoria coletiva no contexto da educação em tempos de cibercultura. Porto Alegre: CEIE-SBC, 2020.

4. PRETTO, Nelson De Luca. Professores universitários em rede: um jeito hacker de ser. Motrivivência, Florianópolis, v. 21, n. 34, 2010. Disponível em: https:// periodicos.ufsc.br/index. php/motrivivencia/article/ view/16038/15850. Acesso em: 21 set 2020 . 
possibilita tempo para qualificação. Na prática, aumentou minha carga de trabalho e estou à beira da exaustão" (Respondente 119 - pública).

Ademais identificamos contribuições à atividade remota emergencial em âmbito geral:

Compreender os limites da prática na modalidade remota (Respondente 7 - privada).

Mais cuidado com a sobrecarga de trabalho e cobranças sobre questões que o professor não consegue resolver (Respondente 53 - privada).

Valorização do professor como uma pessoa e não uma máquina (Respondente 171 - privada).

Uma das palavras fortemente relacionadas à docência na pandemia é saúde. A recorrência ao ensino remoto é decorrência da preocupação em manter a saúde física. Alarga-se o sentido do termo para saúde mental (docente e discente). Contribuições espontâneas ilustram a polissemia, evidenciando riscos:

A carga de trabalho e de aula parece muito mais pesada, a falta de energia depois de passar horas on-line, muito mais alongamento e manter a mente ocupada com outras coisas pra conseguir focar (Respondente 126 - privada).

Ter como prioridade a saúde mental de alunos, professores e demais colaboradores da IES (Respondente 266 - privada).

Emprego e renda são elementos centrais da atividade docente, já impactados pela desvalorização da educação e políticas que preterem a qualificação do ensino, transformando a educação em mercadoria. Quanto à situação laboral, a pergunta "Durante a pandemia houve redução de salários e benefícios por parte da Instituição de Ensino" teve 78,3\% dos participantes discordando fortemente da afirmação. De maneira complementar, questionamos sobre demissões docentes na IES ou ameaças ao emprego: $71,3 \%$ discordo fortemente; $11,8 \%$ discordo moderadamente; $9,8 \%$ indiferente.

Percebe-se que, inicialmente, a maioria das IES não reduziu salários e/ou benefícios e não demitiu docentes. Entretanto, embora reduzidos, os números de cortes e demissões preocupam, enaltecidos por contribuições nas questões abertas:

Carga maior de trabalho sem remuneração compatível (Respondente 233 - privada); Desgaste emocional, o dobro de carga de trabalho para receber o mesmo valor mensal, nenhum suporte financeiro (Respondente 69 - pública).

As incertezas amplificam as tensões no campo de emprego e renda:

No começo foi correria. Agora, estamos habituados. Mas o cansaço dá sinais. E a insegurança também, pois não sabemos se permaneceremos com emprego (Respondente 171 - privada);

Pressão institucional, psicológico afetado com expectativas de não receber salário integral ou nem receber etc. (Respondente 49 - privada).

Em síntese, as percepções preliminares sobre as condições de atuação docente junto às IES - implementação, condições de trabalho, tomada de decisão pelo ensino remoto - atestam que o ensino remoto em Publicidade e Propaganda 
na pandemia da Covid-19 foi a alternativa para manter o vínculo estudantil e a sustentação das IES. Outras variáveis, que incidem fortemente no desempenho docente e discente, foram negligenciadas: isolamento forçado, saúde física e mental, bem-estar de estudantes e de docentes, aumento significativo do trabalho docente, volume expressivo de novidades, mudanças súbitas, adaptação prematura e sem qualificação adequada à modalidade remota.

\section{DISCIPLINAS E RECURSOS NO ENSINO REMOTO}

A sala de aula é elemento central nas experiências docentes. Transposta para o ambiente digital, impõe novos desafios ao ensino-aprendizagem em Publicidade e Propaganda. As contribuições, embora incipientes, permitem compreender a atividade docente em prática, envolvendo planejamento, adequações, dificuldades, aceitação e eficiência no processo de ensino-aprendizagem.

Interrogados sobre o trabalho facilitado por ministrar disciplinas teóricas, $31,9 \%$ dos respondentes se mostraram indiferentes, enquanto concordância e discordância mantiveram-se equilibrados (Gráfico 2). Ato contínuo, considera-se o cenário incerto sobre a própria condição de docente de disciplinas teóricas.

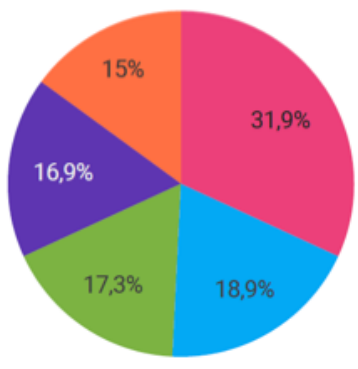

Concordo fortemente

Concordo moderadamente

Indiferente

Discordo moderadamente

Discordo fortemente

Gráfico 2: Considero que meu trabalho é facilitado no ensino remoto por ministrar disciplinas de cunho teórico

As considerações sobre incertezas são reforçadas nas manifestações em perguntas abertas:

Aliar prática profissional com conteúdo teórico, neste momento a ênfase se dá na teoria (Respondente 52 - pública);

As questões técnicas são importantes, mas neste momento me parece que os aspectos teóricos e conceituais precisam ser muito mais fortalecidos (Respondente 30 - privada).

Outrossim, perguntamos aos docentes sobre a facilidade em ministrar disciplinas práticas (Gráfico 3). As respostas expõem uma lacuna do ensino 
remoto na área, uma vez que 67,7\% discordaram da afirmativa e outros $23,2 \%$ mostraram-se indiferentes. Atividades aplicadas proporcionam experimentação e constituem experiências que ocasionam segurança aos discentes, capacitando para soluções com articulação teórico-prática.
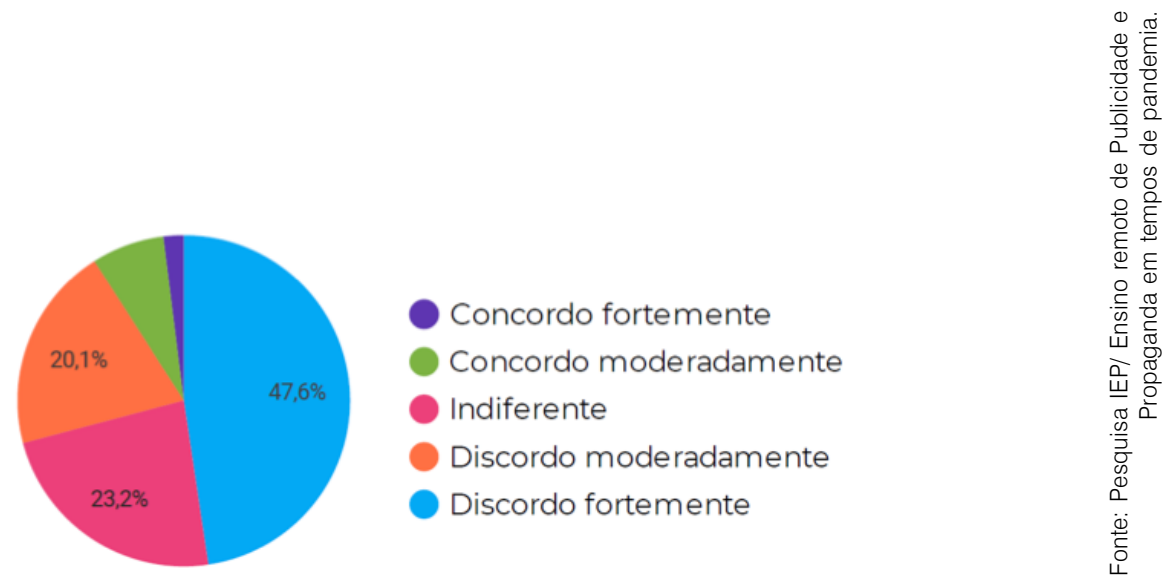

Gráfico 3: Considero que meu trabalho é facilitado no ensino remoto por ministrar disciplinas de cunho prático/laboratorial

Nas contribuições espontâneas, o remoto nas atividades práticas é apontado como obstáculo para a qualidade do ensino.

Lembrar da existência de disciplinas práticas. Muitas universidades usam sua estrutura física para vender o curso, mas agora forçam os estudantes a trabalharem em casa e os docentes a inventarem estratégias que possam ser consideradas, erroneamente, como equivalentes ao desenvolvimento de projetos, para que os alunos que não possuem computadores/softwares não se sintam prejudicados. As atividades práticas devem ser deixadas para depois, e as disciplinas suspensas (Respondente 148 - privada).

Ao ministrar aulas, praticamente $60 \%$ de docentes respondentes se depararam com a necessidade de adequação dos programas das disciplinas. As reflexões sobre ensino qualificado e experiências não podem ignorar que "O desafio maior foi jogar quase todo o planejamento de aulas fora $\mathrm{e}$ refazer tudo nesse novo formato" (Respondente 17 - privada) e que houve "Aumento no volume de trabalho já que todo o semestre teve que ser replanejado para o digital e pouco tempo para a preparação/adaptação" (Respondente 266 - privada).

E o que é ensinado em Publicidade e Propaganda, em termos de conteúdo programático?

É fundamental promover debates sobre o momento histórico da publicidade e os cenários que se apresentam, principalmente sobre comportamento de consumo (Respondente 255 - privada).

Analisar as mudanças do mercado e repensar estratégias de se fazer propaganda. Utilizar a comunicação social como forma de educar e conscientizar a população (Respondente 272 - privada). 
As práticas docentes envolvem recursos, estratégias e metodologias adequadas ao ensino emergencial. Na percepção dos respondentes, atividades síncronas são essenciais (Gráfico 4), reforçando a perspectiva de diálogo, juntamente com apresentações próprias. Nota-se a relevância do docente no papel de mediação ${ }^{5}$, proporcionada por encontros síncronos, interação, minimizando o distanciamento.

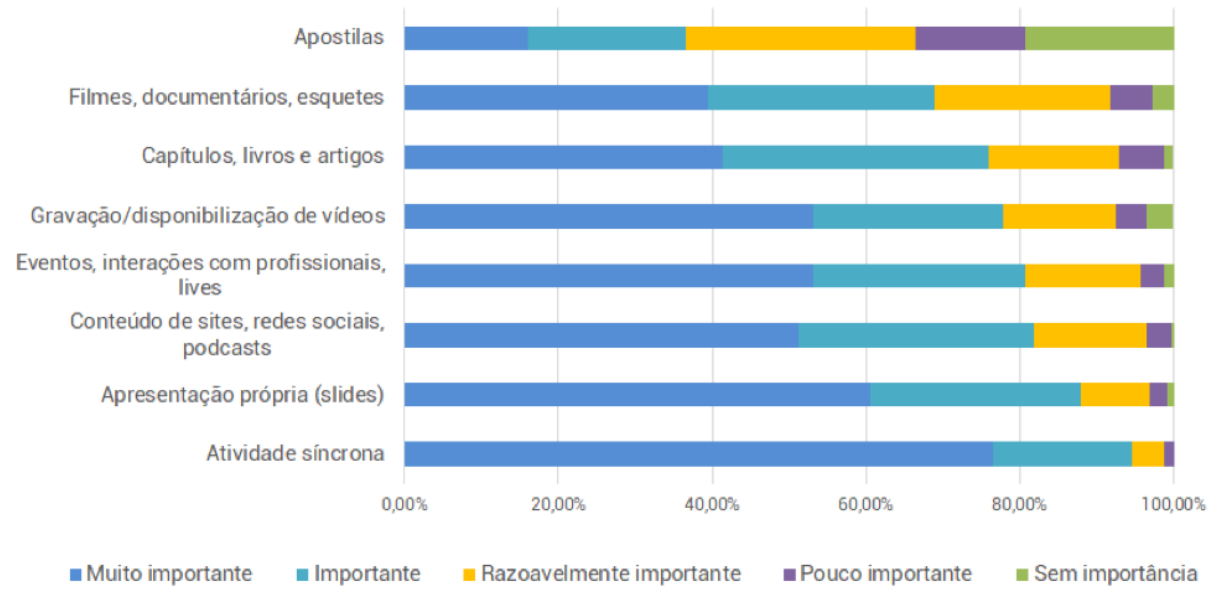

Gráfico 4: Recursos empregados no ensino remoto em relação à aceitação dos estudantes e à percepção de eficiência no processo de ensino-aprendizagem

Questões abertas reforçam estratégias de manutenção do contato com os discentes para proporcionar engajamento:

Dinamismo das aulas remotas síncronas mostram que a participação é mais efetiva. Tornar o momento mais significativo é fundamental (Respondente 161 - privada);

Os encontros síncronos têm sido uma estratégia para manter o contato mais próximo dos alunos, que se sentem acolhidos e acompanham melhor o conteúdo deste modo (Respondente 187 - privada).

Outros recursos, como participação de convidados, lives, entrevistas com profissionais, adotados e mencionados nos questionamentos abertos, apresentam reflexões dos docentes, contrapontos e autocríticas relativas às estratégias adotadas, sobretudo em relação à revisão do tempo de exposição de conteúdo. Usamos nossa estrutura própria para trabalhar e precisamos transpor conteúdos para slides e ocupar muito tempo da aula com falas, o que é contra produtivo, pouco intuitivo e não favorece o aprendizado (Respondente 136 - privada).

Constata-se a transferência do modelo de ensino presencial vigente para o ensino remoto, transmissivo e excessivamente conteudista. Por vezes, vícios da aula presencial são deslocados à atividade remota, sem caracterizar conversação genuína $^{6}$, apontando necessidade de planejamento da situação conversacional. Para alguns respondentes, é necessário adaptar conteúdos, metodologias e avaliações, gerando procedimentos pedagógicos alternativos.
5. BUZATO, Marcelo El Khouri. Letramentos digitais e formação de professores. São Paulo: Portal Educarede, 2006.

6. PIMENTEL, Mariano; CARVALHO, Felipe da Silva Ponte. Princípios da educação online: para sua aula não ficar massiva nem maçante! Porto Alegre: SBC Horizontes, 2020. Disponível em: http://horizontes.sbc.org.br/index. php/2020/05/23/principios-educacao-online. Acesso em: 21 set. 2020. 
comunicação \& educação • Ano XXV • número 2 • jul/dez 2020

Não tivemos tempo de planejamento e sempre estamos atrasados com o conteúdo... não há o entendimento de que as aulas têm que ter a metodologia adaptada para a plataforma on-line e que uma aula que estava 'pronta' antes, agora tem que ser completamente reconstruída (Respondente 173 - privada).

Pontualmente, algumas manifestações sobre como docentes estão ensinando apresentam alternativas. No entanto, reforçamos que a perspectiva de ensino não pode ser resumida a falar para uma câmera e a aprendizagem efetiva não é assistir o professor. É fundamental compreender o estudante e inseri-lo no processo de construção do conhecimento.

Apresentar as possibilidades e conversar com os estudantes, escutá-los e definir juntos as melhores estratégias (Respondente 240 - privada).

Construção conjunta das metodologias com os alunos (Respondente 164 - privada).

Neste cenário, práticas laboratoriais emergem como incógnitas ressaltadas em diversas manifestações: "Desvantagens - disciplinas práticas perdem sem a produção e aprendizado das técnicas” (Respondente 99 - privada); "Adaptação das atividades laboratoriais" (Respondente 55 - pública); "Aulas práticas prejudicadas, estão paradas" (Respondente 77 - privada); "As disciplinas com práticas de laboratório estão muito comprometidas" (Respondente 164 - privada).

Ainda percebemos quatro estratégias representativas para o contexto da pandemia, também mencionadas espontaneamente e que, de certo modo, já poderiam estar incorporadas às aulas presenciais: (1) jogos ou gamificação: estratégia de inclusão e envolvimento. Recorre à ludicidade e pode oferecer recompensas; (2) design thinking: estratégia empregada para solução de problemas; (3) pesquisas: estratégia adotada de maneira síncrona. "Pesquisa em tempo real no momento da aula" (Respondente 151 - privada), como aproximação com o mercado de trabalho ("Pesquisas e planos de ação para empresas locais para auxiliar na pandemia - relação com realidade e mercado" - Respondente 270 - privada) e para reforçar o conhecimento dos estudantes ("O ensino remoto permite ao aluno perceber a importância da pesquisa para a evolução do seu conhecimento” - Respondente 33 - privada); d) apresentações: embora envolva um recurso bastante empregado pelos docentes, teve flexibilidade e adequações importantes: "Gravar podcasts e vídeos de curta duração enquanto método para apresentação de trabalhos" (Respondente 161 - privada).

Outro aspecto relevante para compreensão das experiências docentes no ensino remoto é a avaliação. Abordagem dos "Sistemas de avaliação adotados no ensino remoto" permitiu identificar a prevalência de trabalhos práticos, produção de conteúdo em áudio e vídeo e estudos de caso (Gráfico 5). Em contrapartida, avaliações tradicionais, como provas, foram apontadas como menos importantes pelos respondentes. 


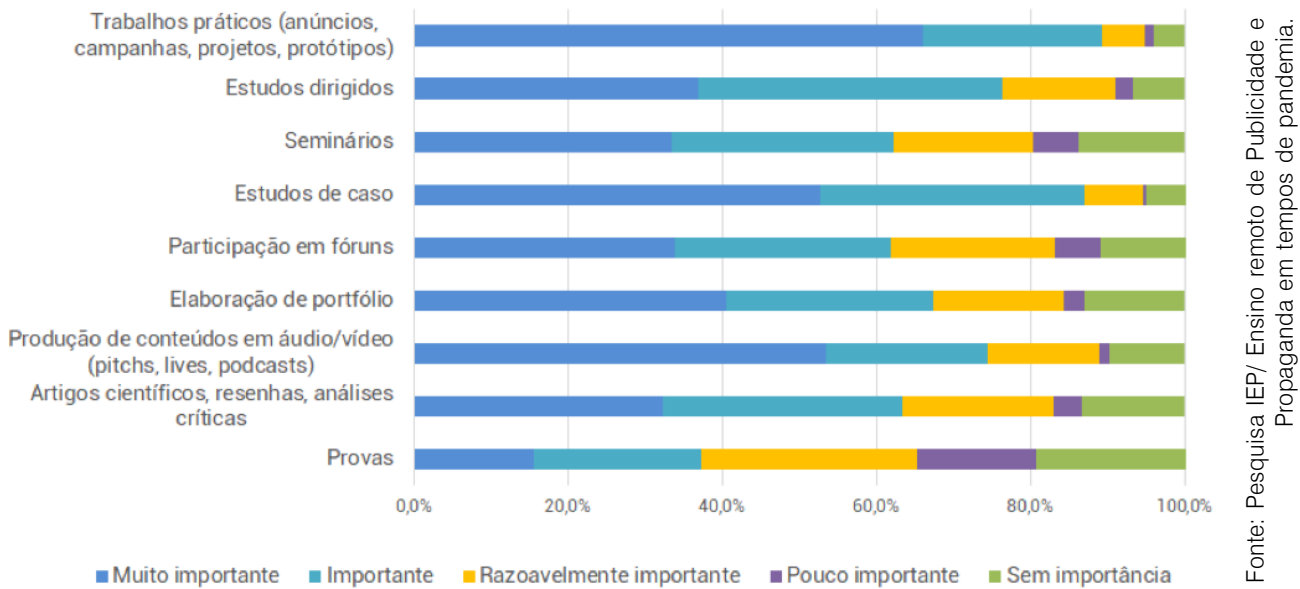

Gráfico 5: Sistemas de avaliação adotados no ensino remoto

As dúvidas sobre a avaliação foram tema recorrente nas manifestações abertas sobre tópicos parcialmente ou não abordados, englobando mudanças necessárias e incertezas. Tais apontamentos são evidenciados em citações:

Suspender práticas tradicionais de avaliação, presença e aprendizado (Respondente 110 - privada);

[problematizar] O uso de processos avaliativos em tempo de aulas remotas (Respondente 128 - privada).

Ainda há indicações pontuais para avaliações eficientes no ensino remoto: trabalhos em grupo em salas virtuais próprias em sistema de orientação; gerenciamento de ambientes virtuais de aprendizagem com previsão de tempo de execução de tarefas e do nível de interação discentes-docente e discentes-discentes; atividades em tempo real, no horário de aula, em detrimento de tarefas extras. Em suma, não se espere aplicar os mesmos métodos ou obter os mesmos resultados neste tipo de processo de ensino-aprendizado.

\section{DIÁLOGO COMO METODOLOGIA DE ENSINO}

Como estão os estudantes de Publicidade e Propaganda diante do ensino remoto? Pela pesquisa não há respostas discentes, mas a percepção docente nos permite problematizar. Questionados se as atividades remotas foram bem recebidas pelos estudantes, 33,1\% concordaram moderadamente, 29,5\% são indiferentes e $17,7 \%$ discordaram moderadamente. Diante do equilíbrio nos índices, intensifica-se a premência de pesquisas com estudantes para avaliar a relação estudantil com o ensino remoto na área.

"O aprendizado estudantil manteve os patamares do ensino presencial"? As respostas à questão reafirmam o papel da universidade como espaço essencial de comunicação, interação, acolhimento e afeto, uma vez que $31,9 \%$ mostraram-se 
indiferentes ao questionamento, 21,3\% concordaram moderadamente e 20,1\% discordaram moderadamente. Menções espontâneas corroboram:

Aprendizagem fortemente comprometida (Respondente 109 - privada);

A impessoalidade e a falta de interação prejudicam o processo de ensino-aprendizagem (Respondente 82 - privada);

A presencialidade qualifica a experiência formativa (Respondente 46 - privada).

Ainda perguntamos se "após as primeiras semanas de ensino remoto, diminuiu a satisfação estudantil com o ensino remoto". 32,7\% mostram-se indiferentes à afirmativa, 24,4\% concordaram moderadamente e 16,9\% discordaram moderadamente.

O maior desafio é a falta de controle da sala de aula e a ausência de um feedback mais intenso por parte dos estudantes (Respondente 178 - privada);

É mais difícil captar as insatisfações da audiência (Respondente 221 - privada).

Diante disso, aventamos algumas hipóteses: (1) falta de retorno de estudantes para professores; (2) distanciamento físico e social; (3) ausência de contato pessoal e direto; (4) postura docente idêntica ao ensino presencial (comportamento autoritário; modelo tradicional de ensinar; incapacidade de comunicação); (5) adaptação ao ensino remoto vincula-se à postura docente na aula presencial, dependendo menos de tecnologia e mais de metodologia, didática e estratégia de ensino.

Outras respostas aos questionamentos contribuem com tal raciocínio, que visa identificar experiências em busca de aprendizagem. Indagamos se os "Discentes têm se mostrado cansados e esgotados nas aulas on-line" e 29,5\% concordaram moderadamente, 28\% mostraram-se indiferentes e 22,4\% concordaram fortemente. Se a condição estudantil interfere no aprendizado, o papel docente ao se retirar da centralidade é preponderante, exigindo escuta e empatia, compartilhamento da gestão da aula ${ }^{7}$ para fomentar o pertencimento estudantil. Citações reforçam tais perspectivas:

Com muita conversa e abertura chegamos a um nível de confiança. Temos tido boas respostas (Respondente 32 - privada).

O ensino remoto permite ao professor sair da zona de conforto e perceber que o ensino-aprendizagem é uma via de mão dupla (Respondente 33 - privada).

Eu vejo que o preparo da aula leva muito mais tempo. A cada semana precisamos nos reinventar na forma de conduzir a aula. Quanto mais o tempo passa, mais os estudantes se mostram cansados, desmotivados e sem foco para os estudos. Nas aulas mais teóricas é difícil promover o debate porque estão ficando mais apáticos. Nas aulas de produção, perde-se na interação com os grupos (Respondente 206 - privada).

Saber interagir coloca-se como condição imperativa no ensino remoto, com estrutura flexível e horizontal, calcada em relação de comunicação, em processo dialógico ${ }^{8}$. Cabe ao docente prever espaços para concessão da palavra 
e intervenções. Questionamentos ganham relevo. Tal condição é asseverada pela percepção de que a participação estudantil revela desatenção e desconcentração no ensino remoto.

Dispersão muito grande dos alunos (Respondente 4 - privada).

Com turmas grandes não há condição de trabalho orientado obter resultados positivos comparativos com aulas presenciais (Respondente 27 - privada).

Meu maior desafio é buscar novas formas de fomentar a participação dos estudantes a cada aula. Com turmas menores está mais fácil. Em turmas maiores exige bastante criatividade para não se repetir (parece que tudo no on-line fica tedioso mais fácil) (Respondente 167 - privada).

Ainda se evidencia a perspectiva de defasagem de conteúdo e conhecimento, com impacto nos próximos períodos letivos. A adaptação das disciplinas para o formato remoto é uma espécie de redução de danos. Logo, há o desafio de planejar estratégias de recuperação do aprendizado no retorno ao presencial. Para tanto, é primordial avaliar o processo de ensino-aprendizagem remoto, o funcionamento e os resultados em processo a fim de ajustar e reorientar, além de monitorar a participação estudantil.

Na pesquisa, direcionamentos sobre e para o corpo discente na pandemia sinalizam: docentes (auto)centrados nas suas disciplinas, no ensinar, com pouco espaço à expressão estudantil; ensino remoto inibe o pensamento criativo. Ainda cabe pontuar o diálogo como metodologia de ensino, superando a indiferença docente frente ao aprendizado estudantil.

Diante disso, traçamos novas hipóteses: (1) falta reconhecer a legitimidade da conversação em rede à promoção da colaboração; (2) falta aceitar a construção de modalidades abertas e criativas de relacionamento entre docente e discentes; (3) o ensino remoto reflete atitudes e posturas do ensino presencial - quem possui dificuldade de dialogar e compartilhar no presencial tende a repetir o comportamento no digital.

\section{APONTAMENTOS FINAIS}

O espaço aberto sobre "desafios, vantagens, desvantagens, rotina, peculiaridades do trabalho docente em Publicidade e Propaganda na pandemia" permite sistematizar recortes temáticos e contribuições pontuais:

1. formação em publicidade e propaganda: comportamento social e relações interpessoais como formação; prejuízo ao processo - cognitivo, sensível, comunicacional e estratégico - para formar publicitários cidadãos; inviabilização de visitas técnicas e produções laboratoriais;

2. desinteresse estudantil: é a marca do trabalho no ensino remoto; baixa participação, dispersão e insegurança discente; falta de engajamento; prejuízo à aprendizagem; 
3. desigualdades: discentes sem acesso à internet, computador, softwares; boicote às aulas em solidariedade aos colegas sem condições;

4. expressividade: desafio de retomar o contato e a interação com os discentes; expressão faz muita falta;

5. excesso de atividades: aumento da carga docente de trabalho; embaralhamento das tarefas pessoais e profissionais; excesso de informações;

6. riscos à saúde: cansaço físico e mental; fragilidade econômica e psicológica; IES não monitoram o desgaste (físico e psicológico), o que deve gerar efeitos futuros.

Durante este período de turbulência, a percepção e o sentimento docente sobre a repentina transformação do processo ensino-aprendizagem são negativos. Se por um lado docentes e discentes não se sentem mentalmente saudáveis, por outro a cobrança por produtividade das IES não diminuiu a fim de preservar a proximidade com discentes via disponibilização de materiais e atividades educativas, em contato assíduo para tirar dúvidas, oferecer apoio e motivar.

Para diagnosticar a atuação docente na perspectiva de adaptação, estratégias de ensino e sistema de avaliação, urge compreender que a substituição das aulas presenciais por aulas remotas é em caráter excepcional. Logo, emergem incógnitas. Reiteramos, perante o objetivo deste artigo, que não há modelos prontos, com eficiência absoluta. As soluções tecnológicas para enfrentar os efeitos do isolamento social não atenderão à gama complexa de atribuições do processo de ensino-aprendizagem.

Embora em contexto adverso, há de se valorizar o esforço docente no desenvolvimento pessoal aliado ao comprometimento profissional e vontade para amenizar impactos negativos. Um desafio docente é se tornar aprendiz, buscando metodologias e recursos tecnológicos, aceitando que estamos numa curva de aprendizado no ensino remoto. Compartilhar angústias com os colegas pode ajudar a superar esta fase. Articular-se enquanto grupo, trabalhar em equipe, conectar-se com o outro, juntar-se, entrosar-se, trocar, complementar. É momento de ser colaborativo e dialógico.

Um dos papéis do docente é atuar no diálogo com estudantes e instituições de ensino para adotar formatos às realidades específicas. Todavia, é essencial que as IES se alinhem a dialogar sobre como fazer o sistema educacional funcionar para garantir o conteúdo, as avaliações, a formação docente, a manutenção de estudantes, debatendo a situação da saúde financeira, mental e pedagógica com a pluralidade da comunidade acadêmica (pais, responsáveis, discentes, docentes, coordenações de curso, lideranças das IES).

\section{REFERÊNCIAS BIBLIOGRÁFICAS}

AMARAL, Mirian Maia; VELOSO, Maristela Midlej Silva de Araujo; ROSSINI, Tatiana Stofella Sodré. A autoria coletiva no contexto da educação em tempos de cibercultura. Porto Alegre: CEIE-SBC, 2020. 
BUZATO, Marcelo El Khouri. Letramentos digitais e formação de professores. São Paulo: Portal Educarede, 2006.

FREIRE, Paulo. Pedagogia do oprimido. Rio de Janeiro: Paz e Terra, 1983.

GIL, Antonio Carlos. Métodos e técnicas de pesquisa social. São Paulo: Atlas, 2008.

HANSEN, Fábio; PETERMANN, Juliana; CORREA, Rodrigo Stéfani. Criação publicitária: desafios no ensino. Porto Alegre: Sulina, 2020.

PIMENTEL, Mariano; CARVALHO, Felipe da Silva Ponte. Princípios da educação on-line: para sua aula não ficar massiva nem maçante!. Porto Alegre: SBC Horizontes, 2020. Disponível em: http://horizontes.sbc.org.br/index. php/2020/05/23/principios-educacao-on-line. Acesso em: 21 set. 2020.

PRETTO, Nelson De Luca. Professores universitários em rede: um jeito hacker de ser. Motrivivência, Florianópolis, v. 22, n. 34, p. 156-169, 2010. Disponível em: https://periodicos.ufsc.br/index.php/motrivivencia/ article/view/16038/15850. Acesso em: 21 set. 2020. 